\title{
Biventricular root replacement for transcatheter pulmonary valve endocarditis after Ross operation: Double the trouble
}

\author{
T. K. Susheel Kumar, MD, ${ }^{a}$ Kaitlin Balduf, MD, ${ }^{b}$ Umar Boston, MD, ${ }^{a}$ and Christopher Knott-Craig, MD, ${ }^{a}$ \\ Memphis, Tenn
}

\footnotetext{
From the Departments of apediatric Cardiothoracic Surgery and 'Pediatric Cardiology, Le Bonheur Children's Hospital and University of Tennessee Health Science Center, Memphis Tenn.

No financial support was used for the conduct of this study.

Disclosures: Authors have nothing to disclose with regard to commercial support.

Received for publication May 27, 2018; revisions received July 13, 2018; accepted for publication July 29, 2018; available ahead of print Nov 1, 2018.

Address for reprints: T. K. Susheel Kumar, MD, Department of Pediatric Cardiothoracic Surgery, Le Bonheur Children's Hospital, University of Tennessee Health Science Center, Memphis, TN 38103 (E-mail: tskumar@uthsc.edu).

J Thorac Cardiovasc Surg 2019;157:e5-7 $0022-5223 / \$ 36.00$

Copyright (C) 2018 by The American Association for Thoracic Surgery https://doi.org/10.1016/j.jtcvs.2018.07.111
}

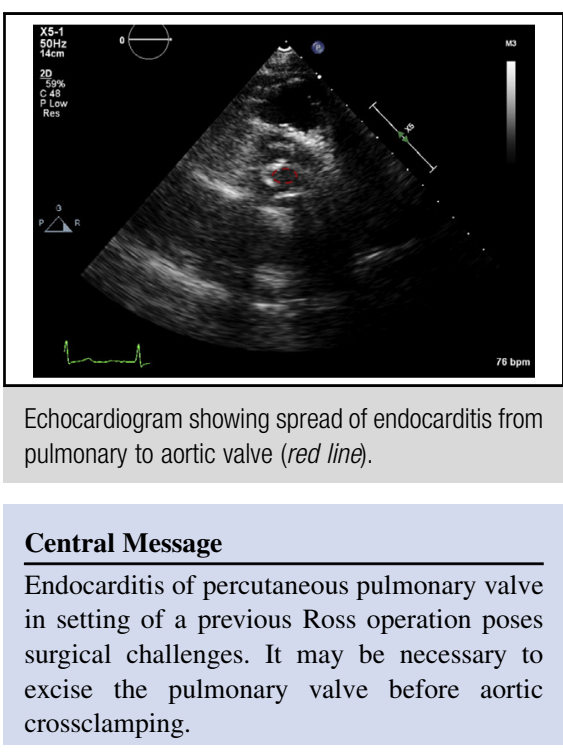

See Editorial Commentary page e9.
Use of percutaneous pulmonary valve replacement (PPVR) has steadily increased during the last decade, even though increased risk of endocarditis continues to be a concern. ${ }^{1,2}$ The close proximity of the right ventricle-pulmonary artery (RV-PA) conduit to the dilated neoaorta after the Ross operation poses unique challenges for PPVR. Stent fractures, accelerated progression of neoaortic regurgitation, aortopulmonary fistula, and coronary compression are welldocumented complications of PPRV after the Ross operation. ${ }^{3}$ We draw attention to the dangers of Melody valve (Medtronic Inc, Minneapolis, Minn) endocarditis in the setting of Ross operation and to the surgical challenges it poses.

\section{CASE DESCRIPTION}

A 22-year-old syndromic man was admitted to the hospital for complaints of increasing fatigue, weight loss, intermittent fevers, and increased seizure activity of 6 months' duration. He had undergone 5 previous sternotomies and cardiac operations, including a Ross operation at 4 years of age and bioprosthetic aortic valve replacement at 16 years. Four years later, he had stenosis of the RV-PA homograft conduit, which was managed by prestenting of the conduit, and PPVR was managed with a 22-mm Melody valve. Two years later, he had obstruction and culturepositive Streptococcus viridans endocarditis of the Melody valve. At this time the aortic root was moderately dilated, and the aortic bioprosthesis was functioning normally (Figure 1). Despite intravenous antibiotics, the endocarditis progressed, and 6 weeks later there was echocardiographic evidence of new severe aortic bioprosthesis obstruction (gradient $110 \mathrm{~mm} \mathrm{Hg}$ ), and severe Melody valve obstruction (gradient $115 \mathrm{~mm} \mathrm{Hg}$; Figure 2).

He was taken to the operating room for emergency surgical replacement of both aortic valve and RV-PA conduit (Video 1). Dense pericardial adhesions were encountered from severe inflammation around the infected Melody valve and RV-PA conduit. The metal stent in the main pulmonary artery had eroded into the wall of the aortic root, thereby precluding placement of the aortic crossclamp until after the pulmonary root had been excised on cardiopulmonary bypass. The aortic crossclamp was then applied and the heart arrested with Custodiol cardioplegic solution (Custodiol HTK; Köhler Chemie GmbH, Bensheim, Germany). The aortic bioprosthesis was found to be infected with large vegetations, and the stent was found eroding into the wall of the aortic root. The valve was excised, and the aortic root was resected completely. Aortic root replacement was achieved with a 23-mm cryopreserved aortic homograft. 


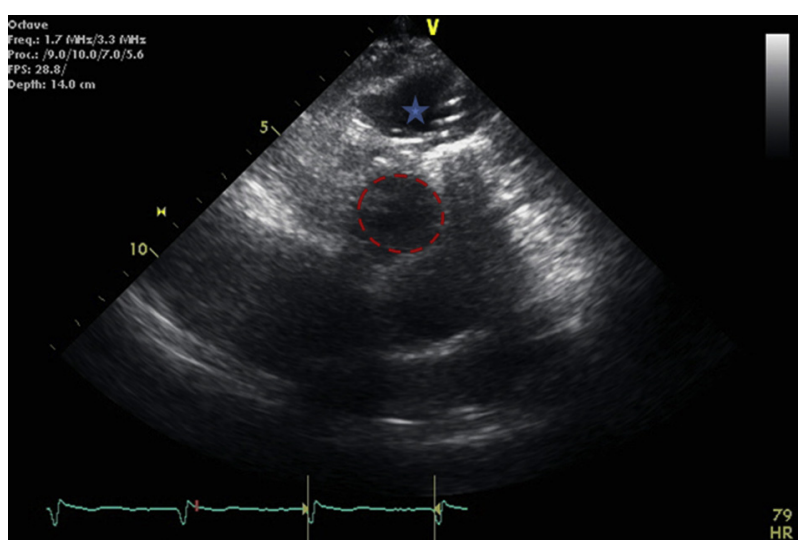

FIGURE 1. Parasternal short-axis 2-dimensional echocardiogram demonstrating the stent of the Melody valve (Medtronic Inc, Minneapolis, Minn) in the pulmonary artery position (star) in close proximity to the native aortic valve (valve orifice shown with red dashed line).

The pulmonary root was replaced with a $23-\mathrm{mm}$ pulmonary homograft during rewarming. The total cardiopulmonary bypass duration was 258 minutes, and the aortic crossclamp time was 107 minutes. The patient was weaned from cardiopulmonary bypass without difficulty and recovered completely without significant morbidity. The antibiotics were continued for duration of 6 weeks. Echocardiography performed more than a year after bilateral outflow tract replacement demonstrated nicely functioning aortic and pulmonary valves with preserved ventricular function and without any signs of endocarditis.

\section{DISCUSSION}

The Ross operation restores a functional aortic valve, but the pulmonary artery conduit may need replacement down the road. ${ }^{4,5}$ The PPVR has been used by some to extend the longevity of the surgically placed RV-PA conduits. ${ }^{3}$ Melody PPVR after the Ross operation, however, sets up unique challenges. Increased risk of stent fractures is well

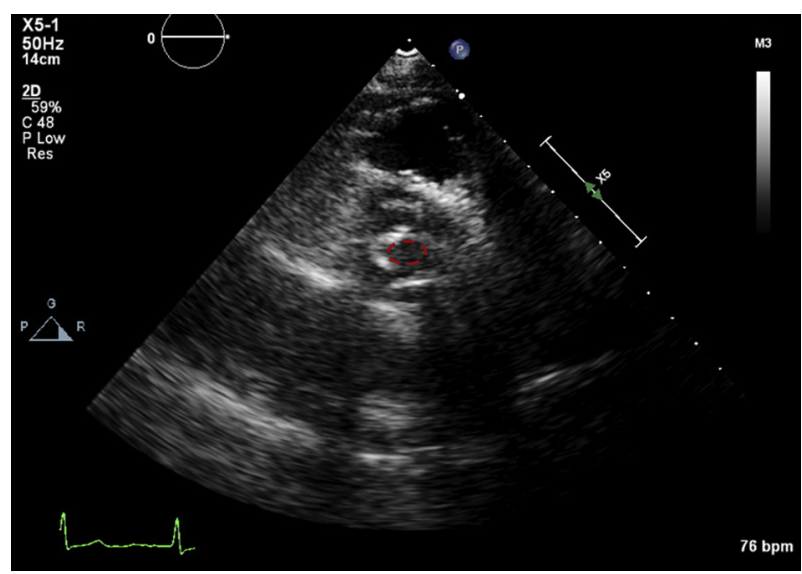

FIGURE 2. Echocardiogram showing spread of endocarditis from pulmonary to aortic valve (red dashed line).

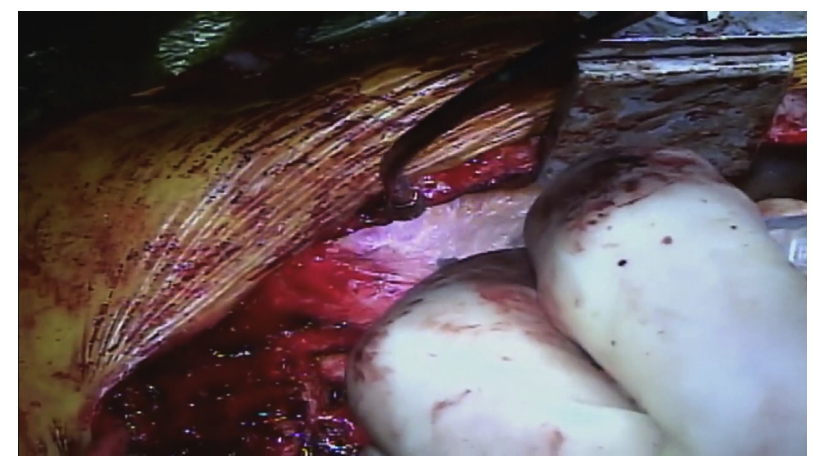

VIDEO 1. Video of the operation showing surgical management of Melody valve (Medtronic Inc, Minneapolis, Minn) infection affecting the aortic root in a patient with a previous Ross operation. Video available at: https://www.jtcvs.org/article/S0022-5223(18)32474-7/fulltext.

documented. ${ }^{6}$ Accelerated progression of the neoaortic insufficiency caused by the rigid metal stent has also been reported. ${ }^{7}$ Aortopulmonary fistula and coronary compression are other concerns. ${ }^{8}$ In addition, reoperation on the Melody valve encased in the metal cage juxtaposed to the aortic autograft is a particularly challenging problem, as evidenced in this report.

Gillespie and colleagues ${ }^{3}$ described a large series of 56 patients who underwent Melody PPRV for conduit dysfunction after the Ross procedure. ${ }^{3}$ Of these 56 patients, $60 \%$ had metal or covered stents before Melody valve placement. The PPVR with Melody valve was associated with satisfactory early and midterm outcomes. Endocarditis occurred in $10 \%$ of the patients during a median follow-up period of 4 years. Three patients required surgical explantation, although details were not mentioned.

The unique combination of aortic root dilation and orthotopic position of the graft brings the aortic wall and homograft into very close proximity. ${ }^{3}$ Prestenting of conduit with a rigid stent further accentuates this, making spread of infection to the contiguous structures very easy although in our patient the aortic bioprosthesis may have enhanced the process. Surgical management can become extremely challenging in such circumstances. A preprocedural transesophageal echocardiogram must be performed to rule out any septal defects. Aortic root vent affords protection against air embolism. During the operation, it may be difficult if not impossible to dissect the aortopulmonary plane to make room for the aortic crossclamp. It may be necessary to excise the stent and Melody valve on a beating heart before crossclamp application. Elective ventricular fibrillation may be necessary in the presence of septal defects. The predisposition of the Melody valve toward endocarditis, reluctance to refer these patients for early reoperative surgery, and initial preference to treat prosthetic valve endocarditis medically can prove disastrous and make for extremely challenging surgery. Earlier intervention may be warranted in these situations. 


\section{References}

1. Van Dijck I, Budts W, Cools B, Eyskens B, Boshoff DE, Heying R, et al. Infective endocarditis of a transcatheter pulmonary valve in comparison with surgical implants. Heart. 2015;101:788-93.

2. Malekzadeh-Milani S, Ladouceur M, Iserin L, Bonnet D, Boudjemline Y. Incidence and outcomes of right-sided endocarditis in patients with congenital heart disease after surgical or transcatheter pulmonary valve implantation. J Thorac Cardiovasc Surg. 2014;148:2253-9.

3. Gillespie MJ, McElhinney DB, Kreutzer J, Hellenbrand WE, El-Said H, Ewert P, et al. Transcatheter pulmonary valve replacement for right ventricular outflow tract conduit dysfunction after the Ross procedure. Ann Thorac Surg. 2015;100: 996-1002; discussion 1002-3.

4. da Costa FD, Takkenberg JJ, Fornazari D, Balbi Filho EM, Colatusso C, Mokhles MM, et al. Long-term results of the Ross operation: an 18-year single institutional experience. Eur J Cardiothorac Surg. 2014;46:415-22; discussion 422.

5. Juthier F, Vincentelli A, Pincon C, Banfi C, Ennezat PV, Marechaux S, et al. Reoperation after the Ross operation: incidence, management, and survival. Ann Thorac Surg. 2012;93:598-604; discussion 605.

6. McElhinney DB, Cheatham JP, Jones TK, Lock JE, Vincent JA, Zahn EM, et al Stent fracture, valve dysfunction, and right ventricular outflow tract reintervention after transcatheter pulmonary valve implantation; patient-related and procedural risk factors in the US Melody Valve Trial. Circ Cardiovasc Interv. 2011;4:602-14.

7. Friedman KG, McElhinney DB, Rhodes J, Powell AJ, Colan SD, Lock JE, et al Left ventricular diastolic function in children and young adults with congenital aortic valve disease. Am J Cardiol. 2013;111:243-9.

8. Kenny D, Holoshitz N, Turner D, Hijazi Z. Aortopulmonary fistula after transcatheter pulmonary valve replacement. Circ Cardiovasc Interv. 2013;6:e67-8. 